\title{
EL PLANO DE HUESCA DE 1891 EN EL CONTEXTO DE INTRIGAS LOCALES Y PENURIA DE LA HACIENDA MUNICIPAL'
}

\author{
José Luis Villanova \\ Departamento de Geografía \\ Pl. Ferrater Mora, 1, 17004 Girona, Universidad de Girona \\ josel.villanova@udg.edu
}

\begin{abstract}
Resumen: El artículo analiza el proceso de formación del plano de Huesca de 1891; el último de los cinco planos de capitales de provincia que levantó el topógrafo Dionisio Casañal entre 1879 y 1891. El estudio se ha desarrollado a partir de documentación original, en gran parte inédita, y noticias de prensa de la época, así como de bibliografía sobre la historia de la cartografía urbana, las características políticas de la España de la Restauración y la situación económica de las haciendas municipales en aquel período. La investigación ha permitido confirmar la gran calidad técnica del plano y también ha puesto de manifiesto su provechosa utilización por parte del Ayuntamiento para la planificación y la gestión de la ciudad. Asimismo ha demostrado que la contratación del trabajo estuvo vinculada a políticas partidistas y que supuso una carga excesiva para los exiguos presupuestos municipales de Huesca.
\end{abstract}

Palabras clave: historia de la cartografía, ciudad de Huesca, Dionisio Casañal, restauración borbónica, haciendas municipales.

Abstract: This paper discusses the process to develop the map of Huesca of 1891; the last of the five maps of the capital city provinces that was surveyed by Dionisio Casañal, topographer, between 1879 and 1891. The

Recibido: 10-12-2016. Aceptado: 20-12-2016.

1. Este artículo se ha realizado en el marco del Proyecto de Investigación Ref. CSO2014-54078-C2-1-P, financiado por el Ministerio de Economía y Competitividad. Agradezco a María Jesús Torreblanca (Archivo Municipal), Roberto Rodríguez (Área de Urbanismo del Ayuntamiento), Luis García (Archivo Diocesano) y Juan José Generelo (Archivo Histórico Provincial) las facilidades dadas para consultar documentación de la ciudad de Huesca. 
study has been made using original and in part unpublished documents and newspapers of the time, as well as literature on the history of urban cartography, the political characteristics of the Spain of the Restoration and the economy of municipal finances in that period of time. In the research is confirmed the high technical quality of the map and its profitable use in urban planning and management. It has also shown that the contract of this work was linked to partisan politics and it supposed an unreasonable burden on the meager municipal budgets.

Keywords: history of cartography, city of Huesca, Dionisio Casañal, bourbon restoration, municipal finances.

\section{Introducción}

Las ciudades españolas experimentan un importante desarrollo urbano en la segunda mitad del siglo XIX, aunque no se trata de un desarrollo regular en el tiempo, ni afecta con igual intensidad a todas ellas (Oyón y García Espuche, 1994; Reher, 1994; Fernández Cuesta, 2011). Este crecimiento provoca tanto alteraciones de las tramas históricas de las ciudades como su ampliación (Bassols Coma, 1996; De Terán, 1996; Monclús Fraga, 1999). Para encauzar las primeras actuaciones, el Gobierno establece la obligatoriedad de contar previamente con instrumentos que proporcionen un buen conocimiento de la morfología de la ciudad y sirvan para preparar la remodelación urbanística: los llamados planos geométricos y de alineaciones (Bassols Coma, 1996). Diversas disposiciones determinan las poblaciones que debían levantarlos, los facultativos competentes para ello, prescripciones relativas a su grafismo, presentación y contenido, e instrucciones sobre la ejecución de las alineaciones previstas ${ }^{2}$. Conforme a estas normas, numerosas ciudades proceden a formarlos ${ }^{3}$, pero sólo unas pocas -como Barcelona (1862) o La Coruña (1874) - confeccionan los planos con los planes generales de las alineaciones previstas, aunque estos últimos no tendrían aplicación práctica. Y la mayor parte se limita a formar el plano geométrico (Anguita Cantero, 1997 y 1998), que se convertirá en una herramienta imprescindible para la planificación y la gestión municipal.

Algunos ayuntamientos encargan el levantamiento a arquitectos municipales e incluso maestros de obras, pero en muchas ciudades la falta de medios técnicos e instrumentales y el exceso de trabajo de estos facultativos provocan que se recurra a otros especialistas (Anguita Cantero, 1998). Las posibilidades de trabajo que se abren a ar-

2. Reales órdenes de 25-7-1846, 20-2-1848, 16-6-1854 y 19-12-1859.

3. Otras muchas no encargan este tipo de trabajos, entre otras razones, por el elevado gasto que debía cargarse en los raquíticos presupuestos de los ayuntamientos (Anguita Cantero, 1997). 
quitectos, ingenieros y topógrafos motivan que se organicen empresas privadas para levantar los planos; entre las que destacará el Centro Geodésico-Topográfico de Dionisio Casañal (Villanova, Palanques y Calvo, 2015).

En 1890, el Ayuntamiento de Huesca encarga la formación del plano de la ciudad a Casañal. Los resultados serán muy satisfactorios, pero el proceso de adjudicación y el pago de los trabajos constituirán un excelente ejemplo de, por una parte, el caciquismo, clientelismo y corrupción que impregnan la política municipal en la España de la Restauración y, por otra, la penuria que padecen las haciendas locales.

El artículo describe, en primer lugar, la evolución urbanística de la ciudad de Huesca en el siglo XIX, especialmente en su segunda mitad. A continuación, expone el estado de la cartografía de la capital oscense en el momento en que el Ayuntamiento firma el contrato con Casañal para el levantamiento del plano de la ciudad. En tercer lugar analiza el complicado proceso de contratación. En cuarto examina las características del plano y los posteriores usos que le dio el Ayuntamiento. Y por último aborda los problemas de Casañal para cobrar los trabajos.

\section{La ciudad de Huesca en el siglo XIX}

La ciudad de Huesca, configurada en el siglo XIII, no experimenta ninguna expansión urbana notable hasta el XIX. Aunque, a lo largo de esos siglos, diversas operaciones modifican su estructura. En la primera mitad del Seiscientos y en el contexto de la Contrarrefoma, se establecen numerosos conventos. Algunos se instalan en el casco medieval, pero la mayoría lo hace en sus alrededores; quedando la ciudad rodeada por un anillo de conventos que, con sus huertas, circunvalan prácticamente toda la ciudad (Naval Mas y Naval Mas, 1985: 807). Junto a la instalación de los conventos, y algunos ensanchamientos y anulaciones de callejas en el siglo XVIII, se producen otros dos fenómenos que afectan a la estructura medieval de forma significativa: la configuración del Coso y la modificación de la muralla al sur y al norte. Las bases del trazado del Coso habían sido establecidas en el siglo XIV. Pedro IV ordenó derribar todas las casas que se levantaban a menos de 15 brazas de la muralla. Su conformación se define en los siglos XVII y XVIII, al construirse en la alineación opuesta a los muros algunos conventos y casas solariegas relevantes en la ciudad, que forman un anillo alrededor del casco medieval. La alteración de la muralla fue provocada por la construcción de dos monasterios y su incorporación a la ciudad en los siglos XVI y XVII (Naval Mas y Naval Mas, 1985: 810; Naval Mas, 1990).

Durante la primera mitad del siglo XIX no se producen modificaciones relevantes de la planta de Huesca (Callizo Soneiro, 1980), pero la desamortización de Mendizábal alterará, a la larga, su estructura urbana. Una buena parte de los conventos masculinos y las alrededor de 100 casas de su propiedad o tributarias de ellos pasan a propiedad par- 
ticular, otros son ocupados por instalaciones militares o destinados a desempeñar funciones administrativas, y otros desaparecen al no considerarse útil su rehabilitación para las necesidades del momento ${ }^{4}$. A su vez, sus huertas acaban en manos de las familias más pudientes (Naval Mas y Naval Mas, 1978; Naval Mas, 1980; Calvo Salillas, 1990; Laborda Yneva, 1997; Fontana Calvo, 2003). De este modo, Huesca pierde la condición de ciudad conventual que la había caracterizado desde el siglo XVII (Fontana Calvo, 2003: 25) y las ventas hacen posible reformas urbanisticas de gran calado, al desaparecer los muros de los conventos que constituían un entramado dificil de franquear si la ciudad quería expandirse urbanísticamente (Calvo Salillas, 1990; Sabio Alcutén, 2004: 15).

En este período, se produce otro acontecimiento que, si bien no provoca grandes consecuencias en la estructura urbana, tiene graves repercusiones en el desenvolvimiento socio-cultural de la ciudad: el cierre de la Universidad en 1845, en el marco del Plan Pidal de reforma de la enseñanza. Fundada en 1354, habia sido centro creadory difusor de nuevas corrientes dentro de un marco ideológicamente mayoritariamente adverso a las innovaciones científicas (Sabio Alcutén, 2004: 16) y el número de edificios relacionados con ella, incluidas las casas que los conventos habían abierto convirtiéndolas en colegios, habían hecho de Huesca una ciudad universitaria; característica complementaria a la de ciudad conventual, que se acaba de mencionar. Lo cierto es que, la Universidad y todo lo relacionado con ella habían influido en el aspecto urbano y en la vida ciudadana (Naval Mas y Naval Mas, 1985: 806).

Así pues, a mediados del siglo, la mayor parte de la ciudad todavía se encuentra en el interior de la muralla, que va desapareciendo lentamente bajo las casas que se edifican sobre ella. Fuera del recinto solo existen los barrios de San Lorenzo, San Martín y Barrionuevo (Madoz, 1850: 200). A partir de este momento, circunstancias acaecidas anteriormente -elección como capital provincial y desamortización-, junto a la progresiva consolidación del Estado liberal, que requiere edificios para acoger nuevas sedes administrativas e institucionales, y las demandas de los habitantes, que comienzan a tener ciertos derechos electorales, provocan la realización de "las primeras remodelaciones planificadas con vistas a la modernización de la ciudad"; unas remodelaciones que no llegan a borrar su trazado secular pero lo alteran notablemente. Huesca incrementa la extensión de su espacio urbano, amplía las vías de comunicación, derriba los restos de la muralla y se desplaza hacia la periferia, comenzando a adquirir una morfología muy ligada a una estructura social y politica distinta, y a una novedosa infraestructura de servicios públicos y privados (Naval Mas y Naval Mas, 1982; Laborda Nieva, 1997: 58; Sabio Alcutén, 2004: 15). Sin embargo, la marginación en cuanto al proceso de industrialización no supondrá ningún cambio demográfico patente 5 y por

4. Los conventos de religiosas corren mejor suerte, pues con el tiempo serán devueltos a sus antiguas propietarias (Naval Mas y Naval Mas, 1978).

5. Si en 1860 la población de Huesca era de 10.160 habitantes, en 1900 sólo había alcanzado los 12.264 (Casas y Abad, 1883: 38; Calvo Salillas, 1990: 75). 
tanto el fenómeno de urbanización será mínimo, lento y costoso (Calvo Salillas, 1990: 14). Entre 1860 y 1900, la tasa de crecimiento urbano anual se encuentra entre 0,219 y 0,565\%, mientras que la media española es de 0,670\% (Reher, 1994: 8 y 9).

Las principales operaciones tienen lugar en los accesos a la ciudad por carretera y ferrocarril. En 1847 se abre el paseo de Santo Domingo para dar entrada a la carretera de Barbastro, que en el interior de la ciudad aprovecha el trazado del Coso Bajo y la desaparición de la antigua plaza del Mercado. En 1858 se aprueba la expropiación de terrenos para la construcción de la carretera Zaragoza-Francia. Para dar cabida a esta vía por el norte se abre la avenida de Monreal. Su recorrido continuaba por el Coso Alto y, tras romper el entramado del barrio de San Francisco, salía de la ciudad por el antiguo camino de Zaragoza (Naval Mas y Naval Mas, 1978; Calvo Salillas, 1990; Sabio Alcutén, 2004). Por otra parte, la entrada en servicio del empalme ferroviario HuescaTardienta en 1864, que conecta la ciudad con Barcelona y Zaragoza, provoca otras grandes transformaciones en la fisonomía urbana. Para comunicar la ciudad con la estación, situada al sur, se abre la calle de Zaragoza, continuación de los Porches de Galicia, y se acaba por definir el ordenamiento de la plaza de Navarra, cuyo proceso de formación se había iniciado en 1858 a raíz de la apertura de la carretera de Zaragoza. Queda así constituido un eje que ponía en contacto la estación con la céntrica plaza del Nuevo Mercado y que había comportado la demolición de varios edificios (Naval Mas, 1980; Calvo Salillas, 1990; Sabio Alcutén, 2004).

A estas operaciones de expansión urbana se añaden otras de saneamiento, reforma interior y eliminación de barrios insalubres -muchas de ellas en consonancia con las teorías higienistas de la época, bajo la inspiración del catedrático de Historia Natural del Instituto de Huesca Serafín Casas y Abad (Calvo Salillas, 1990)-, aunque algunas soluciones resultan condicionadas por la penuria de las arcas municipales (Casas y Abad, 1883; Naval Mas y Naval Mas, 1985). Estas actuaciones van acompañadas de diversos proyectos de alineaciones, entre los que merece destacarse el Plan General aprobado por el Ayuntamiento en 1861 -al que se hace referencia en el siguiente apartado- y que se recoge en el plano geométrico de Huesca del arquitecto provincial José Secall y Asión.

\section{El estado de la cartografía de la ciudad}

En 1890, cuando el topógrafo Dionisio Casañal firma el contrato con el Ayuntamiento para levantar un plano geométrico de Huesca, la cartografía disponible para guiar la planificación y la gestión urbanística de la ciudad era bastante limitada. Por un lado, existían dos planos anónimos que representaban el núcleo oval amurallado y los tres barrios exteriores. Pero ambos presentan distorsiones muy acusadas, pues no habían sido realizados utilizando fundamentos geométricos (triangulación, poligonación, nivelación). El historiador Ricardo del Arco data el que se conserva en el Museo de Huesca hacia 1796 
(Arco, 1922: 6) ${ }^{6}$. El otro, que se encuentra en el Archivo Diocesano, parece ser una copia del anterior, pues presenta similares características técnicas y abarca prácticamente el mismo territorio. La principal diferencia es que en este segundo se han superpuesto una posible ubicación de la plaza del Nuevo Mercado y los límites de las parroquias de la ciudad que se discutían desde $1854^{7}$. El reducido ámbito territorial que abarcan y sus características técnicas convertían a estos documentos en instrumentos poco útiles para planificar y gestionar la ciudad.

Mayores posibilidades ofrecía el Plano general de Huesca de 1861 de José Secall, el primero realizado a partir de fundamentos geométricos, y sobre el que se representaba el Plan General de alineaciones. En este plan, Secall planteaba hacer realidad casi todas las actuaciones en torno a una gran obra: la construcción del Mercado Nuevo, a partir de una idea del maestro de obras, Hilarión Rubio de 1856 (Fontana Calvo, 2003: 26). El proyecto, además de la construcción del mercado y de la apertura de la plaza que lo acogería en un sector del casco medieval con deficientes condiciones higiénicas, incluía la alineación y apertura de seis calles, que partiendo de la plaza tenían la misión de facilitar la circulación interior y poner en relación directa el mercado con las nuevas vías de comunicación. Esta ambiciosa operación urbanística tendría que esperar casi dos décadas a verse completada a causa de los problemas económicos del Ayuntamiento (Naval Mas y Naval Mas, 1978; Naval Mas, 1980; Calvo Salillas, 1990: 94).

Secall ejecutó un levantamiento extremadamente minucioso (Betrán Abadía, 2013) y dibujó el plano conforme a las instrucciones de la Real Orden de 19-12-1859, en la que se detallaban las prescripciones sobre la representación gráfica de los planos de alineaciones, su presentación y contenido. La disposición oficial establecía que los planes de alineaciones generales debían representarse a escala de 1:2.000 y los de alineaciones parciales a 1:300. Por ello, si bien la escala general del plano era de 1:2.000, la de 1:300 sólo se aplicó a las alineaciones concretas previstas en unas pocas zonas del casco urbano y algunos accesos a la ciudad. Por otra parte, la real orden -al igual que las precedentes referidas a los planos geométricos- no hacía referencia alguna a las curvas de nivel y Secall tampoco las incluyó ${ }^{8}$.

Por último, el Depósito de la Guerra levantó otro plano de Huesca en 1870, a una escala de 1:2.000 y con curvas de nivel equidistantes $3 \mathrm{~m}$., en el marco de una ambi-

6. Museo de Huesca, NIG 01977. El Museo sigue esta datación, salvo que investigaciones y conclusiones posteriores varien dichos datos. http://servicios3.aragon.es/reddigitalA/pages/Main (Consulta: 10-5-2016)

7. Archivo Diocesano de Huesca, secciones "Planos y cartografía", sign. 13-1/2 y "Demarcaciones eclesiásticas", sign. 2-3-1/2-01. Sobre ambos planos ver Naval Mas, 2016: 17-18.

8. En 1866, el ingeniero Casto Olano realizó el Plano de Huesca y sus alrededores para el proyecto de travesía por la ciudad en la carretera de Zaragoza a Canfranc. Olano se limitó prácticamente a dibujar sobre el plano de Secall las modificaciones que comportaría la ejecución del proyecto. Archivo Histórico Provincial de Huesca, sección "Obras Públicas", sign. OP/820/1. 
ciosa campaña de formación de planos de ciudades españolas que desarrolló el Cuerpo de Estado Mayor entre 1865 y 1900. En 1883 fue revisado y actualizado y en 1885 publicado a una escala de 1:5.000 (Urteaga y Magallanes, en publicación) ${ }^{9}$.

Los planos de Secall y del Cuerpo de Estado Mayor habían sido levantados con gran precisión técnica pero las escalas utilizadas, así como la ausencia de curvas nivel en el primero y que la equidistancia de las mismas fuera de $3 \mathrm{~m}$. en el segundo, los limitaban extraordinariamente para determinadas operaciones urbanísticas ${ }^{10}$.

\section{La contratación del plano con Dionisio Casañal}

En noviembre de 1880, Dionisio Casañal escribe al alcalde Francisco Pérez Satué, presentándose como topógrafo dedicado a la especialidad del levantamiento de planos de población, para ofrecerse a formar uno de la ciudad que permitiría planificar las actuaciones urbanísticas previstas y las que se pudieran plantear en los próximos años ${ }^{11}$. Dionisio Casañal y Zapatero (Zaragoza, 1846-1913) había ingresado en 1870 en el recién creado Cuerpo de Topógrafos. Durante ocho años, y como jefe de brigada topográfica del Instituto Geográfico y Estadístico (IGE), ejecutó trabajos para la formación del mapa topográfico nacional en diversas provincias. En 1878 se desvinculó del Cuerpo y creó el Centro Geodésico-Topográfico en Zaragoza para dedicarse a la actividad profesional en el ámbito privado. Merecen destacarse, entre otros, sus planos urbanos de Zaragoza (1880), Pamplona (1882), Córdoba (1884), Vitoria (1888) y Huesca (1891), y los numerosos planos parcelarios de municipios de Navarra y sindicatos de riego del Valle del Ebro. Varios de estos trabajos fueron galardonados en exposiciones nacionales e internacionales (Villanova, 2011a).

Junto a la carta remitida al alcalde, y para reforzar su oferta, Casañal también le envía copias de su plano de Zaragoza, las bases facultativas del plano del término municipal de esta ciudad y el proyecto y presupuesto del plano de Pamplona. Ante las posibles dudas acerca de su personalidad y capacitación, le sugiere que se informe con el Director general del IGE o con el Ayuntamiento de Zaragoza. Además, conocedor de la situación de la hacienda municipal, se ofrece a ejecutarlo por unas condiciones económicas verdaderamente excepcionales, 32.500 pts., dejando a su arbitrio los pla-

9. A nivel casi anecdótico para el caso que nos ocupa, puede añadirse que, en 1886, Emilio Valverde incluyó en su Guía del Antiguo Reino de Aragón, un pequeño plano de la ciudad a escala de 1:15.000 (Valverde Álvarez, 1886: 49), que era una simple reducción del publicado por el Depósito de la Guerra, y Serafín Casas otro similar, dibujado por el maestro de obras Vicento Filló, en su Guía de Huesca (Casas y Abad, 1886: 117).

10. No hay que olvidar, por ejemplo, que el reglamento de la Ley de Ensanche de Poblaciones de 22-121876 estableció que los planos generales debían incluir curvas de nivel equidistantes $2 \mathrm{~m}$.

11. Archivo Municipal de Huesca -AMHu, en adelante-, exp. 654. 
zos y condiciones en que debería efectuarse el pago. Y por último, le ruega que entregue una copia del plano de Zaragoza al concejal Manuel Camo; detalle que no es baladí, como se verá más adelante. El mes siguiente, el secretario Mauricio Berned reconoce la utilidad y conveniencia de esta clase de trabajos, pero aconseja al alcalde no contratar sus servicios en aquellos momentos debido a la situación financiera del Ayuntamiento. La propuesta no llega a discutirse en el pleno y queda aparcada ${ }^{12}$.

En abril de 1882, con motivo de una sorprendente exposición del recién terminado plano de Pamplona en el ayuntamiento de Huesca, Casañal escribe a Berned suplicándole que active el asunto del plano para aprovechar la buena impresión que en el ánimo de todos dejó la exhibición de los trabajos de Pamplona. En esta ocasión, el alcalde solicita a Joaquín Pano y Ruata, ingeniero Jefe de Obras Públicas de la provincia, un dictamen sobre las bases bajo las cuales se había propuesto el levantamiento. Pano las encuentra muy aceptables y éstas pasan a informe de la Comisión de Policía urbana. El 1 de agosto Casañal vuelve a escribir al secretario municipal para que haga cuanto pueda para que en la próxima sesión pueda ser presentado y votado el dictamen. Cinco días más tarde, la Comisión presenta un informe en el que reconoce la competencia del topógrafo y la utilidad del plano. Pero también advierte de la dificultad de asumir el coste de los trabajos por impedirlo el estado de la Hacienda municipal. El Ayuntamiento aprueba el dictamen y decide prorrogar su ejecución hasta que resolviera la Junta municipal $^{13}$. Sin embargo, el tema vuelve a quedar aparcado durante varios años.

Hasta 1888 no se tienen nuevas noticias de Casañal en Huesca. Seguramente estaba ocupado en otros trabajos ${ }^{14}$. En febrero de aquel año reitera la propuesta al entonces alcalde Ismael Molerá y Albert, manifestándole que, ante la angustiosa situación económica del Municipio, deja al Ayuntamiento completa libertad de señalar los plazos o presupuestos en que debe verificarse el pago. Pero el asunto vuelve a quedar paralizado, aunque esta vez por menos tiempo ${ }^{15}$. El 19 de mayo de 1890, el Ayuntamiento acuerda pasar a informe de la Comisión de Policía urbana una instancia y las bases que Casañal había presentado para levantar los planos de la población y del término municipal, y ejecutar el amojonamiento y deslinde de dicho término. En esta ocasión las gestiones llegan a buen término con sorprendente rapidez. El 2 de junio, de conformidad con el dictamen de la Comisión, la Corporación aprueba encargarle los trabajos, previa aprobación del presupuesto en la Junta municipal: 36.000 pts. que se le abonarán a razón de 750 pts. mensuales desde finales de agosto. El 9 de julio se firma el contrato y Casañal inicia las operaciones el día siguiente ${ }^{16}$.

12. AMHu, exp. 654 y Libro de Actas. Año 1880.

13. AMHu, exp. 654 y Libro de Actas. Año 1882.

14. Entre 1882 y 1888 estuvo centrado en los planos de Córdoba y Vitoria, en parcelarios de sindicatos de riego de la Ribera del Ebro y en el del término municipal de Zaragoza, que finalizaría en 1892.

15. AMHu, exp. 654.

16. AMHu, exps. 654, 1.350 y 1.577, exp. HAC 879/LALA y Libro de Actas. Año 1890. 
En las tres negativas que recibió Casañal, el Ayuntamiento aludió a la penuria de la hacienda municipal -circunstancia cierta, sobre la que se volverá-, pero algunos detalles del proceso de contratación y la sorprendente rapidez con que se resuelve el asunto en 1890 inducen a pensar que pudieron influir razones de carácter político.

En el último cuarto del siglo XIX, el Ayuntamiento de Huesca cuenta con mayorías de concejales del Partido Demócrata y, posteriormente, del Republicano Posibilista (PRP) (Frías Corredor, 1990). Pero los alcaldes no suelen pertenecer a estas formaciones pues, por la Ley Municipal de 2-10-1877, son nombrados directamente por el Gobierno de turno, conservador o liberal, entre los electos. Así pues, a diferencia de lo que ocurre en buena parte del territorio nacional [... l la filiación de la mayoría política dominante en el Consistorio no coincide con la del partido convocante de las elecciones en cada momento, por lo que no se produce la alternancia política entre conservadores y liberales característica de la Restauración y las minorías no gubernamentales se convierten en la fuerza mayoritaria del Consistorio (Frías Corredor, 1990: 371). Esta situación es debida, en gran medida, a los apaños y presiones de Manuel Camo Nogués (1841-1911), líder del PRP en la provincia y uno de los caciques más caracterizados del Altoaragón. Camo monopoliza la vida política de la capital y la provincia durante aquella época. Desde 1877 siempre ocupa cargos institucionales: concejal del Ayuntamiento, diputado provincial, presidente de la Diputación, diputado en Cortes y senador vitalicio (Frías Corredor y Trisán Casals, 1987: 215; Romero Salvador, Frías Corredor, Serrano García, 2001).

En la España de la Restauración, el caciquismo, el clientelismo y la corrupción impregnan la vida política, pero no sólo son patrimonio de conservadores y liberales, sino que los republicanos también utilizan estas estrategias (Varela Ortega, 1977). El hecho de que el predominio municipal en Huesca corresponda a estos últimos provoca numerosas tensiones entre el Ayuntamiento y el Gobierno civil, siempre en manos del partido gobernante de turno (Frías Corredor y Trisán Casals, 1987) ${ }^{17}$. La contratación de los trabajos del plano de Huesca no escapó a este contexto político, como se verá a continuación.

En 1880, el secretario municipal aconseja al alcalde desestimar el ofrecimiento a causa de la situación financiera de la Corporación y el asunto queda aparcado, sin llegar a discutirse en el pleno. Sin embargo, en la petición realizada dos años más tarde, Casañal alude a las "mezquinas intrigas de localidad" que habían paralizado el asunto. El comentario tal vez pudo deberse a que, a pesar de existir una amplia mayoría demócrata (Frías Corredor, 1990), el alcalde designado por el Gobierno es el conservador Francisco Pérez Satué ${ }^{18}$. También merece mencionarse que Casañal debía de ser correligionario del entonces concejal Camo (Serrano Pardo, 2014), a quien le envía una

17. No hay que olvidar que el gobernador supervisaba la gestión de los ayuntamientos (Moreno Luzón, 1995 y 1996).

18. El Diario de Huesca, 13-2-1877, p 2 у 4-9-1877, p. 2, у AMHu, exp. 654. 
copia del plano del Zaragoza en 1880, seguramente para que intentara influir en la resolución de la Corporación ${ }^{19}$.

En 1882, el PRP cuenta con una abrumadora mayoría de concejales (Frías Corredor, 1992), pero el Gobierno había nombrado alcalde al liberal Antonio Gasós Espluga ${ }^{20}$. En esta ocasión, Casañal aprovecha el éxito de la exposición de sus trabajos de Pamplona en el Ayuntamiento de Huesca para escribir al secretario municipal suplicándole que active el asunto. No debe extrañar el envío de esta carta, pues el secretario constituía otra pieza básica del engranaje local de poder. por sus manos pasaba toda la administración y se encargaba de los trabajos burocráticos; atribuciones que le otorgaban gran capacidad de maniobra (Moreno Luzón, 1995: 26). Por otra parte, la celebración de la exposición pone de manifiesto que Casañal contaba con apoyos en la Casa. En esta ocasión, el informe de la Comisión de Policía urbana es favorable, pero la Junta municipal -constituida por concejales y representantes de los mayores contribuyentes, bajo la presidencia del alcalde (Moreno Luzón, 1995) - no aprueba la partida necesaria. Y el asunto vuelve a quedar paralizado, a pesar del apoyo que El Diario de Huesca brinda a Casañal.

Casañal no vuelve a dirigirse al Ayuntamiento hasta febrero de 1888, cuando la Corporación ésta presidida por el liberal Ismael Molerá y Albert. Y, de nuevo, el asunto vuelve a quedar aplazado, aunque sólo momentáneamente. En las elecciones municipales de 1889, los posibilistas obtienen la mayoría absoluta y, por primera vez, es nombrado un alcalde de este partido, Luis de Fuentes Mallafrée ${ }^{21}$. Finalmente, el 2 de junio del año siguiente, el Ayuntamiento acuerda contratar los servicios de Casañal.

Podría pensarse que el proceso de contratación había llegado a su fin, pero los conservadores no se dan por vencidos; buena muestra del carácter político que encerraba la decisión. En la reunión de la Junta municipal, celebrada el 25 de junio de 1890, pocos días antes de la firma del contrato, el concejal conservador Mariano Vidal Domingo recuerda la existencia del plano de Secall, por lo que considera innecesario encargar otro. El alcalde, deseando evitar gastos inútiles, solicita un informe al arquitecto municipal Federico Villasante ${ }^{22}$. La documentación consultada no proporciona más informaciones, pero es posible que el informe recomendara la formación del plano, pues pocos días más tarde se firma el contrato. No obstante, los conservadores seguirán in-

19. Casañal ya había actuado de forma similar en Córdoba y Vitoria. En las propuestas que dirigió a los respectivos alcaldes, les informó de que, para los trabajos de campo, contaría con antiguos compañeros del Cuerpo de Topógrafos nacidos en ambas capitales o hizo referencia a sus relaciones con personajes influyentes en las mismas (Villanova, 2011b; Villanova, Palanques y Calvo, 2015).

20. El Diario de Huesca, 4-5-1881, p. 8 y 1-7-1881, p. 6.

21. Es posible que en el nombramiento realizado por el Gobierno de Sagasta, influyera la creciente colaboración legislativa de Castelar, líder del Partido Republicano Posibilista, con los liberales; colaboración que, entre otras cosas, abría oportunidades a los posibilistas "en materia de responsabilidades de gestión en provincias y municipios en los períodos de gobierno liberal" (Duarte y Gabriel, 2000: 13).

22. AMHu, exp. 1.577. 
tentando paralizar el proceso. En octubre de 1890, atendiendo a unas denuncias presentadas a raíz de la intervención de Vidal y de la resolución adoptada, el gobernador civil José Álvarez Pérez eleva una querella a la Audiencia de Zaragoza. El gobernador consideraba que la concesión era un asunto amañado y que se había realizado «en condiciones ventajosísimas". Pero, en enero de 1891, la Audiencia de Zaragoza sobresee el caso dictaminando que los hechos no constituían delito ${ }^{23}$.

Antes de continuar, y en este contexto, conviene examinar el papel de El Diario de Huesca en el asunto, pues es otra muestra del ambiente que reinaba en la política municipal. El periódico, inspirado por su fundador y propietario Manuel Camo, era la publicación periódica más importante de la provincia (Fernández Clemente y Forcadell Álvarez, 1979; Frías Corredor, 1993), y a lo largo de todo el proceso, manifestará un completo apoyo a Casañal: en 1882, a la vista de los trabajos del plano de Pamplona, que se exponen en el Ayuntamiento oscense, destaca la extraordinaria competencia del topógrafo y reclama que el Ayuntamiento se plantee la necesidad de contar con un plano de similares características ${ }^{24}$. En 1888, califica sus planos de Zaragoza y Córdoba de obras notabilísimas para cubrir las necesidades de todo régimen municipal, progresivo y culto y critica que no se contrataran anteriormente los servicios de Casañal por no comprender bien su excepcional importancia o por exagerados miramientos a la consignación de gastos extraordinarios cuando los trabajos resultarían grandemente beneficiosos y reproductivos para la administración municipal ${ }^{25}$. En 1890 arremete contra el gobernador civil por las denuncias y, tras la resolución de la Audiencia, desata una auténtica campaña de desprestigio contra él, al tiempo que elogia la decisión municipal $^{26}$. Y, finalmente, una vez entregados los trabajos, escribe: Hoy todo el mundo hace justicia a Casañal por el mérito sobresaliente de los hermosísimos trabajos que ha exhibido. Hoy todo el mundo repite que es una verdadera maravilla de la ciencia y del arte el trabajo que representa el plano de población de Huesca y de todo su término ${ }^{27}$. Por su parte, Casañal contratará anuncios del Centro Geodésico-Topográfico en las páginas del diario, seguramente para agradecer estos apoyos.

\section{Las características del plano de 1891 y su empleo}

No se han localizado en el Archivo Municipal de Huesca las condiciones facultativas para el levantamiento, pero en el plano a escala de 1:2.500 se recoge que su formación se había regido por las mismas bases que en el caso de Córdoba. Esta infor-

\footnotetext{
23. AMHu, exp. 1.577 y El Diario de Huesca, 22-9-1890, pp. 12-13; 23-9-1890, pp. 9-10; y 4-11-90, p. 9.

24. El Diario de Huesca, 15-4-1882, p. 2.

25. El Diario de Huesca, 3-3-1888, pp. 11 y 12

26. El Diario de Huesca, 4-11-1890, pp. 8-10; 19-2-1891, p. 9; 23-2-1891, pp. 9-10; у 24-3-1891, pp. 9-11.

27. El Diario de Huesca, 15-7-1891, p. 10.
} 
mación arroja luz sobre el asunto, aunque no de forma completa. Las bases para el levantamiento en la ciudad andaluza establecían que el trabajo se organizaría en tres fases -triangulación, poligonación y nivelación-, que eran descritas de forma detallada. Posteriormente, concretaban el contenido de los diferentes documentos en escala de 1:300, 1:500, 1:1.250 y 1:5.000 -para el plano general-, y la documentación complementaria que debía adjuntarse (cuadernos y álbumes con los borradores y los cálculos efectuados) (Villanova, 2011b). Muy probablemente las operaciones de campo y los documentos complementarios fueran idénticos en ambos casos, pero no los planos entregados. En Huesca, los presenta en las escalas de 1:100 -las hojas referidas a las calles y las plazas-, 1:500, 1:1.000 y -para el plano general- 1:2.500. A su vez, en los dos planos de conjunto se representan las curvas de nivel a una equidistancia de $1 \mathrm{~m}$. -curvas que también se dibujan en los planos a escala de 1:1.000- y contienen observaciones similares acerca de su elaboración (altitudes referidas al nivel medio del mar en Alicante, paso convencional de las curvas de nivel por el interior de las manzanas, etc.). Pero en el de Córdoba se incluye un nomenclátor de calles y plazas y un listado de edificios públicos, localizables gracias a las coordenadas de una cuadrícula; información ausente en el de Huesca. A la vista de estas diferencias puede pensarse que la referencia al plano de Córdoba era parcialmente errónea, pues las características de los planos presentados se aproximaban mucho más a las del caso de Pamplona (Villanova, 2014). Por otra parte, en 1880, Casañal ya había propuesto levantar el plano conforme a las bases del realizado en esta ciudad ${ }^{28}$.

Tras algo más de un año de trabajo, en julio de 1891, Casañal entrega los materiales correspondientes al plano de la ciudad: 99 carpetas con planos de 131 calles, plazas, travesías, costanillas y rondas a escala de 1:100²9; 17 hojas del plano a escala de 1:500; cinco hojas de1 plano a escala de 1:1.000, con curvas de nivel equidistantes $1 \mathrm{~m}$. (Figura 1); diversos álbumes, carpetas y cuadernos con los borradores de campo y los cálculos y las operaciones efectuados; la piedra litográfica para el grabado del plano a escala de 1:2.500; y 200 copias de este último documento (Figura 2). Y en agosto presenta las 14 hojas del plano del término, a escala de 1:5.000, con lo que quedaba ultimado el compromiso ${ }^{30}$.

Como en las otras ciudades donde Casañal había formado el plano, en Huesca también se nombra una comisión facultativa encargada de examinar los documentos. Es-

28. AMHu, exp. 654.

29. En estos planos se representan numerosos detalles de gran utilidad para la gestión de la ciudad: bocas riego, farolas de columna y de pared, recipientes urinarios, focos eléctricos, fuentes públicas, aceras y travesías adoquinadas, cotas al nivel del mar, numeración de las casas, desaguaderos, tuberías de conducción aguas y alcantarillado.

30. AMHu, exp. 654 y El Diario de Huesca, 20-11-90. En noviembre de 1890 ya había entregado los planos y las actas relativos al deslinde y amojonamiento del término municipal con las 16 localidades colindantes. Ayuntamiento de Huesca, Urbanismo, carpeta "Término municipal de Huesca. Actas originales y planos del deslinde con los Ayuntamientos de..., 1890". 


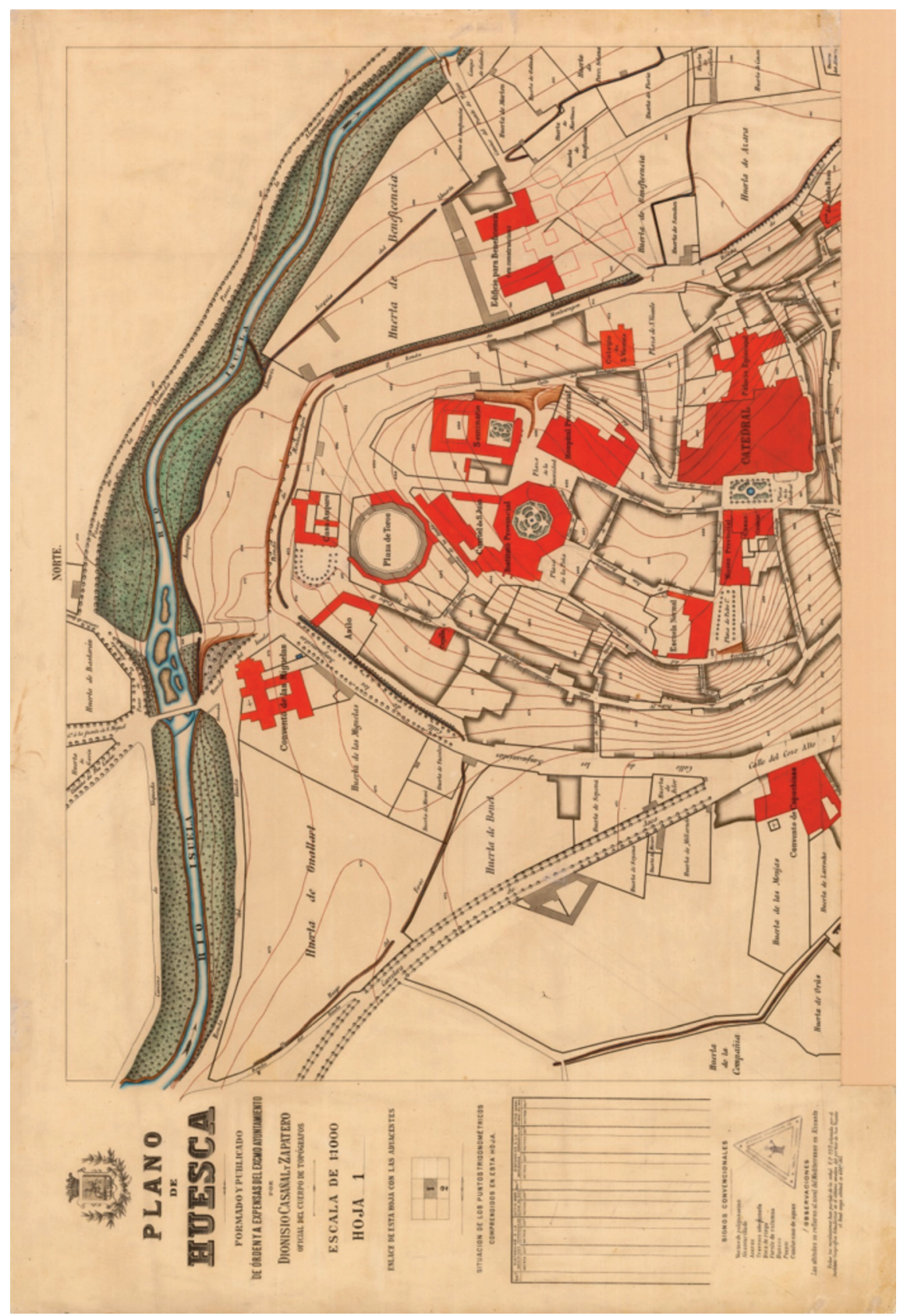

Figura 1. Hoja n 1, Plano de Huesca (1891), escala de 1:1.000.

Fuente: Ayuntamiento de Huesca, Servicio de Urbanismo, "Plano de Huesca de Dionisio Casañal". 


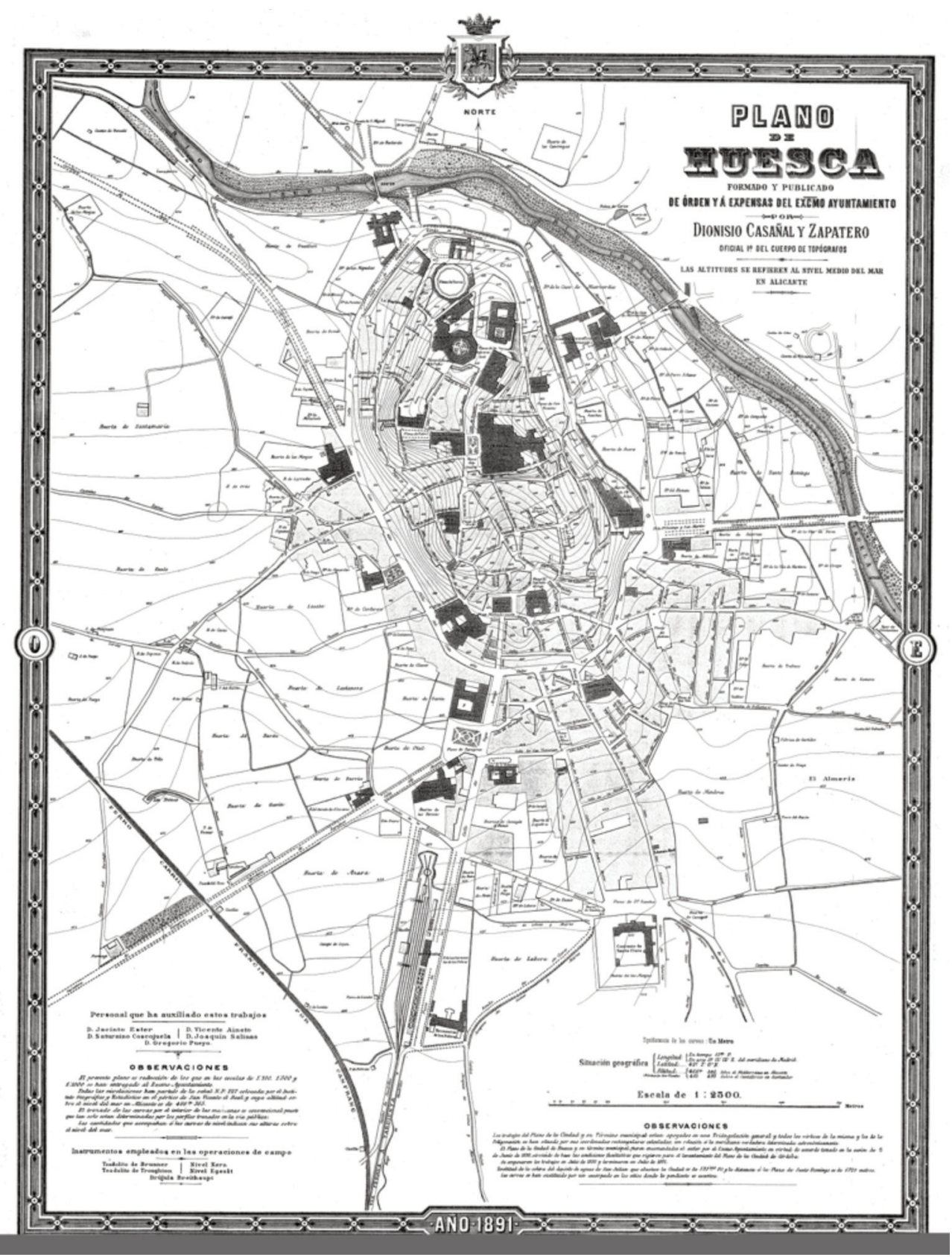

Figura 2. Plano de Huesca (1891), escala de 1:2.500. Fuente: Ayuntamiento de Huesca, Servicio de Urbanismo, "Plano de Huesca de Dionisio Casañal". 
tuvo formada por los ingenieros jefe de Obras públicas y de Montes, los arquitectos provincial y municipal y el propio alcalde. No se ha localizado su dictamen, si es que lo emitió, pero en este caso sería positivo. Un hecho puntual apunta en esta dirección. El 17 de marzo de 1891, la Corporación le solicita los planos de unas zonas de la ciudad que ya había levantado, pues los necesitaba el arquitecto municipal Federico Villasante para diseñar dos proyectos. Al recibirlos el Ayuntamiento apreció lo completo de los trabajos ${ }^{31}$. Además, tras la entrega de los documentos, la prensa local publica noticias elogiosas. El Diario de Huesca, como ya se ha comentado, en grado excesivo. En un tono más comedido, La Crónica se declara "incompetente para juzgar una obra de tal importancia", pero añade: las referencias y opiniones conocedoras de esta clase de obras son tan laudatorias [...] que con gusto nos hacemos eco de ellas ${ }^{32}$. Por otra parte, ninguno de los documentos consultados relativos a la dilatada relación que mantendrían Casañal y el Ayuntamiento se hace referencia al asunto.

El plano de Huesca es un documento cartográfico realizado con esmero y precisión, y, sin duda alguna, el de mayorperfección técnica de los elaborados en la ciudad hasta aquella fecha (Naval Mas y Naval Mas, 1978; Naval Mas, 1980: 98). Lo cierto es que los servicios técnicos del Ayuntamiento lo utilizaron durante años en la gestión y la planificación de la ciudad. En 1891, el arquitecto municipal lo utiliza de base cartográfica para diseñar dos proyectos. Y el mismo año vuelve a emplearlo para elaborar un proyecto de red general de alcantarillado ${ }^{33}$. El hecho de que incluya curvas de nivel equidistantes $1 \mathrm{~m}$. fue de gran utilidad para esta operación (Turmo Arnal, 2004: 44). Por otra parte, el plano fue la base sobre la que diversos arquitectos municipales (Federico Villasante, Ildefonso Bonells, José Benedicto, Francisco Lamolla, José Beltrán, Bruno Farina) trazaron numerosos proyectos de alineaciones parciales, al menos entre 1895 y bien entrada la década de 1930, y sobre la que el ingeniero José Sarto diseñó la red de distribución de aguas en $1934^{34}$. También fue la base cartográfica del plan urbanístico en el que se englobaron el parque y la calle de Miguel Servet y las travesías que los comunicaron con el Coso Alto en la década de 1920 (Calvo Salillas, 1990), y se utilizó en el Plan General de Ordenación Urbana redactado por Emilio Larrodera en 1958. Aunque no está del todo claro si fue su base cartográfica (Lacilla Larrodé, 2011) o solo se usó parcialmente (Tejada Villaverde, 1995). En la actualidad, el documento no se conserva en el Archivo Municipal sino en el Servicio de Urbanismo, pues todavía se consulta en algunas ocasiones; especialmente para cotejar la numeración de las fincas en escrituras antiguas con la actual, ante conflictos o consultas.

31. AMHu, exp. 1.577 y Libro de Actas. Año 1891.

32. El Diario de Huesca, 15-7-1891, p. 11 y La Crónica, 15-7-1891, p. 3.

33. AMHu, exp. 654 y Libro de Actas. Año 1891.

34. Ayuntamiento de Huesca, Urbanismo, exp. 1.922 y 2.165, "Alineaciones antiguas. Carpetas 1 a 49" y "Red de distribución de aguas" (1934). 
Además, "su precisión y riqueza informativa" lo convierten en un instrumento de referencia en los estudios de evolución urbana (Mas Naval, 1980: 98; Calvo Salillas, 1990 y 2004) o hidrografía histórica (Rey Lanaspa, Serreta Oliván y Cuchí Oterino, 2000; Cuchí et alii., 2005; Cuchí y Garcés, 2008). Buena muestra de ello es no solo su utilización en aportaciones académicas sino también su exhibición en exposiciones ${ }^{35}$.

\section{La penuria de la hacienda municipal oscense y sus dramáticas consecuencias}

El Ayuntamiento utilizó inmediatamente y durante muchos años el plano, pero tardó décadas en satisfacer los honorarios de su autor e incluso de forma incompleta. El coste ascendió a 36.000 pts. y la Corporación municipal acordó abonárselas en plazos mensuales de 750 pts. Posiblemente, como en las otras ciudades en las que Casañal había trabajado, decidiera pagarle regularmente previo compromiso del autor de devolver las cantidades adelantadas si el plano no era admitido. En los otros casos se firmó una cláusula especificando que se le abonarían determinados plazos durante la ejecución de los trabajos y el resto cuando la comisión facultativa los aprobara ${ }^{36}$. Parece ser que el Ayuntamiento no puso objeción a los trabajos presentados, por lo que los pagos debían finiquitarse en cuatro años. Pero el plazo se dilatará considerablemente. La causa fue su elevado importe en relación con la penuria de la hacienda municipal ${ }^{37}$; circunstancia habitual en las haciendas municipales en la España de la Restauración.

Desde la Constitución de 1845, la escasez de recursos para hacer frente a sus obligaciones fue una de las características de las haciendas municipales; situación que se consolidó durante la Restauración (Moral Ruiz, 1984; García García y Comín Comín, 1995; Comín, 1996). El panorama se reproduce en Huesca -la principal preocupación del Consistorio a lo largo de la Restauración fue la penuria de los fondos municipales (Frías Corredor, 1990: 379) - y tiene graves consecuencias para Casañal.

Los retrasos en el pago de deudas solían ser moneda corriente en la época y el topógrafo ya los había padecido anteriormente. En Córdoba tardó 20 meses en cobrar el 50\% que se le debía después de la aprobación de los trabajos por la comisión facultativa (Villanova, 2011b). Y, en 1896, el Ayuntamiento de Zaragoza le adeudaba 16.075 pts., cantidad atrasada correspondiente a la formación del plano del término munici-

35. Huesca a tus pies (1996), Evolución de la Delineación a través de los Dibujos (1999) y Huesca, 18912016. El plano de Dionisio Casañal y las fotografías de Mariano Morlans (2016).

36. En Zaragoza y Pamplona le abonaron 1.500 pts. y 1.000 pts. al mes, respectivamente. En Córdoba, el 50\%, 17.475 pts., durante el curso de las operaciones y el resto tras el informe de la comisión. Y en Vitoria, 6.000 pts. al año (Villanova, 2011b y 2014; Villanova, Palanques y Calvo, 2015; Villanova y Betrán, 2017).

37. El presupuesto de 1890 ascendía a 349.751,23 pts. AMHu, Libro de Actas. Año 1890. 
pal y otros trabajos ejecutados entre 1880 y $1893^{38}$. Pero estas demoras también las sufrieron otros facultativos. Por ejemplo, en Sabadell, el arquitecto municipal Miquel Pascual había presentado el plano topográfico de la ciudad en marzo de 1886. Y en diciembre de 1888 se le adeudaban 3.801,75 pts., casi el 25\% de la cantidad en que habían sido presupuestados los trabajos (Nadal, 2014). En Granada el retraso fue más dilatado, aunque no solo fue debido a problemas de la hacienda municipal. En enero de 1850, el Ayuntamiento adjudicó la realización del plano geométrico al arquitecto José Contreras por 60.000 reales. La mitad se pagaría por mensualidades y la otra mitad al aprobarse los trabajos. En julio de 1850 y abril 1851 Contreras ya reclamó cantidades que no se le habían abonado por falta de fondos. En agosto de 1853, una vez presentado el plano, volvió a requerir nuevas mensualidades atrasadas y 5.000 reales a cuenta de la cantidad pendiente; reclamación en la que insistió en diciembre de aquel año y en agosto del siguiente. El problema radicaba en que la comisión facultativa no había emitido el preceptivo informe pues no había fondos para pagar el estudio. En septiembre de 1855, y a pesar de continuar pendiente la aprobación, el Ayuntamiento acordó pagarle en mensualidades a medida que existieran fondos, pero no se tienen más noticias del asunto. El plano no llegó a aprobarse, pues presentaba importantes deficiencias (Camarero Bullón, Ferrer Domínguez y Nieto Calmaestra, 2102). Y en Murcia la demora en el pago todavía fue mucho mayor, y éste sólo se efectuó parcialmente. En 1895, el Ayuntamiento encargó al ingeniero y arquitecto Pedro García Faria la realización de un plan urbanístico por 47.500 pts. El año siguiente, éste presentó los trabajos, que comprendían, entre otros materiales, planos de la ciudad a las escalas de 1:500 y 1: 2.500, así como los perfiles transversales y longitudinales de las calles, planos de detalle de calles y plazas a escala de 1:300 y de los alrededores de la ciudad donde podría iniciarse el ensanche de la ciudad. A pesar de que los trabajos fueron aceptados por la Corporación, García Faria no llegaría a cobrar la totalidad de los honorarios. Siendo alcalde de la ciudad Francisco Martínez y García (1926-1928), éste concertó un convenio con el letrado Pedro Baró Sánchez por el que la deuda, que todavía ascendía a "unas treinta y tantas mil pesetas redújose a diez mil"; cantidad que el autor del plan recibió en 1927, el año de su fallecimiento (Martínez y García, 1930: 187, nota 1; Rosselló Berger y Cano García, 1975).

El caso de Huesca también es muy dramático. En julio de 1891, Casañal acaba de presentar toda la documentación y en diciembre ya reclama 1.500 pts. La razón del alcalde Luis de Fuentes para denegar su petición es la falta de fondos ${ }^{39}$. Hasta pasados cinco años no se vuelven a tener noticias del asunto, pero las cantidades abonadas durante ese período debieron de ser mínimas. En una carta que remite al alcalde José M ${ }^{\underline{a}}$ Aisa, en octubre de 1896, se queja de haber percibido solo una exigua parte de la cantidad que se

38. Archivo Municipal de Zaragoza, caja 980, "Deslindes", exp. 908/1896.

39. AMHu, exp. HAC 664/LALA. 
le adeuda. El año siguiente, Aisa reconoce que la Corporación estaba obligada a satisfacer la deuda, pero la situación pecuniaria de la hacienda municipal le impedía efectuar pagos en aquellos momentos. La situación económica de Casañal debía de ser angustiosa, pues ya había propuesto infructuosamente entregar el plano parcelario del término municipal de Huesca a cambio de cobrar la deuda pendiente en cinco años. Y después de la negativa notifica al alcalde que ha padecido una grave enfermedad, que había puesto en peligro su vida ${ }^{40}$ y que enviará a sus hijos a solicitar una limosna si no le libra una pequeña cantidad. La misiva no obtuvo respuesta satisfactoria y una hija se presentará en el Ayuntamiento para recabar algún pago. El alcalde, escandalizado, le entrega 500 pts. por cortesía, al tiempo que le pide que no se vuelva a repetir el incidente ${ }^{41}$.

El asunto queda nuevamente aparcado y en noviembre de 1903, Casañal vuelve a reclamar alguna cantidad del crédito pendiente. Pero el alcalde Gaspar Mairal le responde que la situación de las finanzas municipales no lo permite en aquellos momentos. Cuatro años más tarde y ante la imposibilidad de cobrar la deuda, escribe de nuevo a Mairal suplicándole que se le consigne desde el próximo presupuesto de 1908 la cantidad a que ascienda el interés legal que a su crédito corresponda. En esta ocasión la Corporación decide aprobar el pago del interés al 5\% de la cantidad adeudada, que ascendía todavía a $26.010 \mathrm{pts}^{42}$. La situación parece desatascarse parcialmente, pero el pago de los intereses se efectúa en contadas ocasiones. En el presupuesto municipal para el ejercicio 1921-1922, la cantidad pendiente y los intereses retrasados ascendían a 40.301 pts. ${ }^{43}$. Casañal fallece en 1913 sin haber visto resuelto el problema.

Desde 1915 la hacienda municipal de la capital oscense experimenta un desenvolvimiento progresivo que le permite satisfacer las atenciones municipales con cierta regularidad, gracias a un mayor control en la formación de los presupuestos y en los pagos efectuados. Esta situación permite al Ayuntamiento pensar en aligerar la masa de deudas atrasadas y, el 3 de marzo de 1922, invita a los acreedores a proponer el tanto por ciento de condonación voluntaria de los créditos resultantes a su favor y en bien del común. Tras recibir las respuestas, el 29 de julio, aprueba por unanimidad clasificar los créditos en dos clases: los que han de devengarse intereses que incrementaban el capital inicial y los que no contemplan intereses por demora. A los primeros les abonaría el 50\% del crédito y los intereses y a los segundos el 60\% ${ }^{44}$. La deuda contraída con

40. Lo cierto es que, por aquellas fechas, Casañal hizo testamento. En el documento consta que estaba enfermo y que tenía varios créditos contra Corporaciones y particulares por derechos devengados en sus trabajos. Archivo Histórico de Protocolos Notariales de Zaragoza, "Testamento de Dionisio Casañal y Zapatero, el 8 de julio de 1897, ante el notario Roque Logroño y Torres".

41. AMHu, exp. HAC 879/LALA.

42. AMHu, exps. 1.350 y HAC 2.087bis/LALA, y Libro de Actas. Año 1907.

43. AMHu, exp. HAC 2.087bis/LALA y "Carpeta general de las cuentas municipales correspondientes al ejercicio de 1921-22".

44. AMHu, Libros de Actas. Año de 1921, tomo II; 1922, tomos I y II; y 1923, tomo I. 
Casañal pertenecía a la primera clase y su viuda Ramona Shakery acepta la propuesta. Finalmente, aquel mismo año recibe 20.155 pts., el 50\% de la cantidad a que ascendían la deuda y los intereses ${ }^{45}$. Habían transcurrido 31 años desde la entrega del plano.

\section{Conclusiones}

La calidad técnica del trabajo de Casañal y su provechosa utilización por parte del Ayuntamiento en la planificación y la gestión de la ciudad han quedado fuera de toda duda. Ahora bien, más sombras existen acerca de la contratación de los trabajos, tanto por lo que se refiere a las circunstancias políticas en las que se desarrolla el proceso, como por la capacidad financiera del Consistorio municipal para hacer frente al importe de los mismos.

Casañal logra la adjudicación después de tres intentos frustrados con unos ayuntamientos presididos por alcaldes conservadores y liberales, cuando la Corporación cuenta con un alcalde del Partido Republicano Posibilista y con una mayoría absoluta de concejales de este partido; formación política a la que también pertenecía el autor del plano. En las tres primeras ocasiones, el Ayuntamiento reconoce la utilidad y la conveniencia de contar con dicho documento, pero rechaza las propuestas por el enorme coste económico que supondrían para las ya depauperadas arcas municipales. No hay que olvidar que en muchas ciudades españolas no se encargaron trabajos similares por esta misma razón. El propio Casañal ya había visto rechazado su ofrecimiento por tal motivo en San Sebastián en 1888 y lo mismo sucedería en Jaca en $1894^{46}$. Sin embargo, este grave inconveniente es obviado por el Ayuntamiento en 1890, cuando decide contratar sus servicios por 36.000 pts. No se trataba de una cantidad elevada para la abundante, completa y rigurosa documentación del trabajo -Casañal había presentado la propuesta más económica de las que acudieron a concurso en Córdoba y había cobrado la misma cantidad por levantar el plano del casco urbano y del término campanil en Vitoria (Villanova, 2011b; Villanova, Palanques y Calvo, 2015)-, pero desbordaba las posibilidades económicas del Ayuntamiento de Huesca: superaba el 10\% del presupuesto municipal de aquel ejercicio, 349.751,23 pts.

Por otra parte, llama la atención la rapidez y la aparente ligereza con que se acuerda la contratación y el importe de los trabajos. En siete semanas, se decide remitir la propuesta a la Comisión de Policía urbana para que dictamine, ésta informa favorablemente, la Corporación admite el dictamen, la Junta municipal aprueba el presupuesto y la modalidad de pago y, finalmente, se firma el contrato. Evidentemente habían in-

45. AMHu, "Carpeta general de las cuentas municipales correspondientes al ejercicio de 1922-23".

46. Archivo Municipal de San Sebastián, exp. H-02027-14 y Archivo Municipal de Jaca, Libro de Actas, 1894. 
fluido directamente las intrigas políticas tan habituales en la política municipal durante la Restauración y a las que se había referido Casañal en su intento de lograr el contrato en 1882. En tres ocasiones le perjudicaron, pero en 1890 le favorecieron.

Las consecuencias de la decisión se arrastrarían a nivel económico durante décadas. El reiterado impago de las cuotas mensuales de 750 pts. y el larguísimo período de tiempo transcurrido hasta que el Ayuntamiento se encuentra en condiciones de afrontar el pago de las numerosas deudas atrasadas, incluso recurriendo a quitas que oscilaban entre el 50 y el 60\%, ponen de manifiesto el desmesurado coste de los trabajos en relación con la situación de la hacienda de la capital oscense; una situación de penuria crónica que caracterizaba al conjunto de los municipios españoles durante la Restauración. Transcurridos 31 años después de la entrega del plano y previa aceptación por parte de la acreedora, la viuda de Dionisio Casañal, el Ayuntamiento cierra el expediente abonando el 50\% de la deuda y los intereses de demora acumulados.

\section{Bibliografía}

Anguita Cantero, R., 1997. Ordenanza y Policía Urbana. Los orígenes de la reglamentación edificatoria en España (1750-1900). Granada: Universidad de Granada y Junta de Andalucía.

Anguita Cantero, R., 1998. La planimetría urbana como instrumento para la transformación de la ciudad en el siglo XIX: la incidencia de los planos geométricos de población en España”. Boletín del Instituto de Estudios Giennenses 169, pp. 563-589.

Arco, R. del, 1922. Las calles de Huesca. Huesca: talleres tip. de la viuda de Justo Martínez.

Bassols Coma, M., 1996. El derecho urbanístico de la Restauración a la II República (1876-1936): crisis de los Ensanches y las dificultades para alumbrar un nuevo modelo jurídico-urbanístico. Ciudad y Territorio 107-108, pp. 53-90.

Betrán Abadía, R., 2013. El plano geométrico de Huesca de 1861. Zaragoza: Institución Fernando el Católico.

Callizo Soneiro, J., 1980. Huesca, un estudio de Geografía urbana. Geographicalia 6, pp. 3-62.

Calvo Salillas, M.J., 1990. Arte y sociedad. Actuaciones urbanísticas en Huesca (1833-1936). Huesca: Ayuntamiento de Huesca.

Calvo Salillas, M.J., 2004. El Círculo Oscense y el modernismo. La historia de un siglo. Argensola 114, pp. 131-180.

Camarero Bullón, C., Ferrer Domínguez, A. y Nieto Calmaestra, J.A., 2102. El levantamiento del plano geométrico de la ciudad de Granada (siglo XIX): una bistoria interminable. Granada: Universidad de Granada.

Casas y Abad, S., 1883. Huesca, su topografía médica o reseña demográfico-sanitaria seguida de un resumen bistórico-descriptivo de sus principales monumentos artísticos. Huesca: Imp. y Lib. de José Iglesias.

Comín, F., 1996. Historia de la Hacienda pública, II. España (1808-1995). Barcelona: Crítica. 
Cuchí, J.A. y Garcés, C., 2008. Aportaciones a la evolución del sistema de riegos del Isuela en la ciudad de Huesca. Anales de la Fundación Joaquín Costa 25, pp. 43-58.

Cuchí, J.A., Montes, L., Justes, J. y Lafragüeta, I., 2005. Agua y roca. El condicionamiento del entorno y el desarrollo histórico de la ciudad de Huesca. Saldvie 5, pp. 159-175.

Duarte, A. y Gabriel, P., 2000. ¿Una sola cultura política republicana ochocentista en España? Ayer. Revista de Historia Contemporánea 39, pp. 11-34.

Fernández Clemente, E. y Forcadell Álvarez, C., 1979. Historia de la prensa aragonesa. Zaragoza: Guara Editorial.

Fernández Cuesta, G., 2011. Crecimiento urbano y modernización en España entre 1857 y 1900. Ería. Revista cuatrimestral de Geografía 84-85, pp. 5-46.

Fontana Calvo, M.C., 2003. La iglesia de San Pedro el Viejo y su entorno. Historia de las actuaciones y propuestas del siglo XIX en el marco de la restauración monumental. Huesca: Instituto de Estudios Altoaragoneses.

Frías Corredor, C., 1990. La época de la Restauración. Estancamiento económico y estabilización política (1874-1923). En: Laliena Corbera, C. (coord.) Huesca. Historia de una ciudad. Huesca: Ayuntamiento de Huesca, pp. 361-382.

Frías Corredor, C., 1992. Liberalismo y republicanismo en el Alto Aragón. Procesos electorales y comportamientos politicos, 1875-1898. Huesca: Ayuntamiento de Huesca.

Frías Corredor, C., 1993. La prensa republicana de la Restauración en el Alto Aragón: El Diario de Huesca. En: Naval. M.A. (coord.) Cultura burguesa y letras provincianas. Periodismo en Aragón (1834-1936). Zaragoza: Mira editores, pp. 255-265.

Frías Corredor, C. y Trisán Casals, M., 1987. El caciquismo altoaragonés durante la Restauración. Huesca: Instituto de Estudios Altoaragoneses.

García García, C. y Comín Comín, F., 1995. Reforma liberal, centralismo y Haciendas municipales en el siglo XIX. Hacienda Pública Española 133, pp. 81-106.

Gil Novales, A., 1980. La Revolución de 1868 en el Alto Aragón. Zaragoza, Guara Editorial.

Laborda Yneva, J., 1997. Huesca. Guía de Arquitectura. Zaragoza: Caja de Ahorros de la Inmaculada.

Lacilla Larrodé, E., 2011. Reflejo de las corrientes de diseño europeas en el urbanismo de Huesca a partir de tres actuaciones en la segunda mitad del siglo XX. I Jornadas sobre urbanismo español contemporáneo. Urbanismo en el Norte de España. Pamplona: Universidad de Navarra. Disponible en: http://dadun.unav.edu/handle/10171/18664 (Consulta: 16.5.2016).

Madoz, P., 1850 [1997 ed. facsímil]. Diccionario geográfico-estadístico-bistórico. 1845-1850. Provincia de Huesca. Zaragoza: Prames.

Martínez y García, F., 1930. A la hora de las responsabilidades. Las reformas urbanas de Murcia. Murcia: Tip. de "La Verdad".

Monclús Fraga, F.J., 1999. Las ciudades españolas en la Edad Contemporánea: procesos de crecimiento y estrategias urbanas. En: García Verdugo, F.R. y Acosta Ramírez, F (coords.) Córdoba en la Historia: La Construcción de la Urbe. Actas del Congreso. Córdoba 20-23 de mayo, 1997. Córdoba: Ayuntamiento de Córdoba y Fundación "La Caixa”, pp. 357-372. 
Moreno Luzón, J., 1995. El clientelismo político en la España de la Restauración. Madrid: Instituto Universitario Ortega y Gasset.

Moreno Luzón, J., 1996. "El poder político hecho cisco". Clientelismo e instituciones políticas en la España de la Restauración. En: Robles Egea, A. (comp.) Política en penumbra. Patronazgo y clientelismo político en la España contemporánea. Madrid: Siglo XXI, pp. 169-190.

Moral Ruiz, J. del, 1984. Hacienda central y haciendas locales en España, 1845-1905. Madrid: Instituto de Estudios de Administración local.

Nadal, F., 2014. La cartografia municipal de Sabadell durant la segona meitat del segle XIX (18581886). Treballs de la Societat Catalana de Geografia 77, pp. 181-204.

Naval Mas, A., 1980. Huesca: desarrollo del trazado urbano y de su arquitectura, 2 vols. Madrid: Universidad Complutense de Madrid.

Naval Mas, A., 1990. Las transformaciones urbanísticas (siglos XVI al XX). En: Laliena Corbera, C. (coord.) Huesca. Historia de una ciudad. Huesca: Ayuntamiento de Huesca, pp. 311-329.

Naval Mas, A., 2016. Huesca, Urbs. Huesca: Colegio Oficial de Aparejadores y Arquitectos Técnicos de Hueca.

Naval [Mas], A. y Naval [Mas], J., 1978. Huesca, siglo XVIII. Zaragoza: Caja de Ahorros de Zaragoza, Aragón y Rioja.

Naval Mas, A. y Naval Mas, J., 1982. Huesca en el siglo XIX. La remodelación de los viejos cascos de las pequeñas ciudades. Storia della Città. Rivista Internazionale di Storia Urbana e Territoriale 23, pp. 17-26.

Naval Mas, A. y Naval Mas, J., 1985. Transformación y etapas de la estructura y función de la ciudad de Huesca. En: Bonet Correa, A. (coord.) Urbanismo e historia urbana en el mundo hispano. Segundo Simposio, 1982, t. 2. Madrid: Universidad Complutense de Madrid, pp. 789-822.

Oyón, J.L. y García Espuche, A., 1994. Crecimiento de las ciudades (1840-1936). En: Bonamusa, F. y Serrallonga, J. (eds.) La Sociedad Urbana en la España contemporánea. Barcelona: Asociación de Historia Contemporánea, pp. 11-21.

Reher, D.-S., 1994. Ciudades, procesos de urbanización y sistemas urbanos en la Península Ibérica, 1550-1991. En: Guardia, M., Monclús, F.J. y Oyón, J.L. (dirs.) Atlas histórico de ciudades europeas. Península Ibérica. Barcelona: Centre de Cultura Contemporània de Barcelona, pp. 1-29.

Rey Lanaspa, J., Serreta Oliván, A. y Cuchí Oterino, J.A., 2000. Nota sobre una acequia perdida bajo el casco antiguo de la ciudad de Huesca. Bolskan 17, pp. 229-235.

Romero Salvador, C., Frías Corredor, C. y Serrano García, M., 2001. Aragón. En: Varela Ortega, J. (dir.) El poder de la influencia. Geografía del caciquismo en España (1875-1923). Madrid: Centro de Estudios Políticos y Constitucionales y Marcial Pons, pp. 45-63.

Rosselló Berger, V.M. y Cano García, G.M., 1975. Evolución urbana de la ciudad de Murcia (8311973). Murcia: Ayuntamiento de Murcia.

Sabio Alcutén, A., 2004. De la ciudad conventual a la ciudad liberal: el espacio urbano y las nuevas necesidades de la sociedad oscense del siglo XIX. En: Huesca Siglo XIX: la ciudad vivida, la ciudad soñada. Huesca: Gobierno de Aragón, Departamento de Educación Cultura y Deporte, pp. 13-29. 
Sabio Alcutén, A., 2014. La modernidad en locomotora: Huesca y el ferrocarril del siglo XIX. Argensola 124, pp. 89-114.

Serrano Pardo, L., 2014. Dionisio Casañal, el cartógrafo de Zaragoza. En: Betrán Abadía, R. y Serrano Pardo L. La Zaragoza de 1908 y el plano de Dionisio Casañal. Zaragoza: Institución Fernando el Católico, pp. 167-191.

Tejada Villaverde, J., 1995. Cartografía en las corporaciones locales. Mapping Interactivo, 25, pp. 58-59.

Terán, F. de, 1996. Evolución del planeamiento urbanístico (1846-1996). Ciudad y Territorio 107108, pp. 167-184.

Turmo Arnal, A., 2004. La trama urbana decimonónica: innovaciones y pervivencias. En: Huesca Siglo XIX: la ciudad vivida, la ciudad soñada. Huesca: Gobierno de Aragón, Departamento de Educación Cultura y Deporte, pp. 31-47.

Urteaga, L. y Magallanes, L. (en publicación). Los planos urbanos del Cuerpo de Estado Mayor del Ejército (1865-1900), Scripta Nova. Revista Electrónica de Geografía y Ciencias Sociales.

Valverde Álvarez, E., 1886. Guía del Antiguo Reino de Aragón. Provincias de Zaragoza, Huesca y Teruel. Madrid: Imprenta de Fernando Cal y Domingo de Val.

Varela Ortega, J., 1977. Los amigos políticos. Partidos, elecciones y caciquismo en la Restauración (1875-1900). Madrid: Alianza.

Villanova, J.L., 2011a. Dionisio Casañal y Zapatero: del catastro a la topografía (1864-1878). En: Montaner, C., Nadal, F y Urteaga, L. (eds.) Cartografia $i$ agrimensura a Catalunya i Balears (segles XIX-XX). Barcelona: Institut Cartogràfic de Catalunya, pp. 209-223.

Villanova, J.L., 2011b. El plano de Córdoba (1884) de Dionisio Casañal y Zapatero. Cuadernos Geográficos 49 (2), pp. 123-152.

Villanova, J.L, 2014. La cartografía de las plazas fuertes españolas: el caso del plano de Pamplona de 1882. Treballs de la Societat Catalana de Geografia 77, pp. 347-368.

Villanova, J.L. y Betrán Abadía, R., 2017. Los planos de Zaragoza de Dionisio Casañal (1880-1911): su utilización en la planificación y la gestión municipal. Ciudad y Territorio. Estudios Territoriales, p. 191.

Villanova, J.L., Palanques, M.L. y Calvo, M., 2015. El plano de Vitoria de Dionisio Casañal (1888). Scripta Nova. Revista Electrónica de Geografía y Ciencias Sociales, XIX (501). 
